\title{
IL-17 mediates inflammatory reactions via p38/c-Fos and JNK/c-Jun activation in an AP-1-dependent manner in human nucleus pulposus cells
}

Jing-kun Li ', Lin Nie ${ }^{1}$, Yun-peng Zhao ${ }^{1}$, Yuan-qiang Zhang ${ }^{1}$, Xiaoqing Wang ${ }^{2}$, Shuai-shuai Wang ${ }^{1}$, Yi Liu', Hua Zhao ${ }^{1}$ and Lei Cheng ${ }^{1,3^{*}}$

\begin{abstract}
Background: Low back pain and sciatica caused by intervertebral disc (IVD) disease are associated with inflammatory responses. The cytokine interleukin 17 (IL-17) is elevated in herniated and degenerated IVD tissues and acts as a regulator of disc inflammation. The objective of this study was to investigate the involvement of IL-17A in IVD inflammatory response and to explore the mechanisms underlying this response.

Methods: Cells were isolated from nucleus pulposus (NP) tissues collected from patients undergoing surgeries for IVD degeneration. The concentrations of COX2 and PGE2, as well as of select proteins involved in the mitogen-activated protein kinase (MAPK)/activating protein-1 (AP-1) pathway, were quantified in NP cells after exposure to IL-17 with or without pretreatment with MAPK or AP-1 inhibitors.

Results: Our results showed that IL-17A increased COX2 expression and PGE2 production via the activation of MAPKs, including p38 kinase and Jun N-terminal kinase (JNK). Moreover, LL-17A-induced COX2 and PGE2 production was shown to rely on p38/c-Fos and JNK/c-Jun activation in an AP-1-dependent manner.
\end{abstract}

Conclusion: In summary, our results indicate that IL-17A enhances COX2 expression and PGE2 production via the p38/c-Fos and JNK/c-Jun signalling pathways in NP cells to mediate IVD inflammation.

Keywords: IL-17, COX2, PGE2, LBP, MAPK, AP-1

\section{Background}

Low back pain (LBP) and sciatica are among the world's leading causes of disability, constituting $11.9 \%$ of disability cases worldwide [1,2]. Intervertebral disc (IVD) herniation is considered to be the main cause of LBP and sciatica [3]. Currently, disc herniation has been shown to be involved in a series of inflammatory processes [4-6], and the causes of the IVD inflammatory response have been reconsidered based on a series of cellular and molecular mediators of inflammation [7-11]. However,

\footnotetext{
*Correspondence: chengleiyx@126.com

${ }^{3}$ Qilu Hospital Shandong University, No.107, Wen Hua Xi Road,

Jinan 250012, Shandong, People's Republic of China

Full list of author information is available at the end of the article
}

the precise mechanisms underlying IVD immune-mediated inflammation remain elusive.

Herniated disc tissues express a variety of inflammatory factors, including interleukin- $1 \alpha$ (IL-1 $\alpha$ ) [12], IL-1 $\beta$ [13], IL-6 [14], IL-10[13], nitric oxide[15], tumour necrosis factor-alpha (TNF- $\alpha)[16,17]$, and prostaglandin E2 (PGE2) $[17,18]$. Among these, TNF- $\alpha$, IL-6, and PGE2 have unique pathological characteristics that are mainly associated with the human body's immune response. PGE2 is an inflammatory factor that can sensitize nerves and then induce pain [18, 19]. Two enzymes, cyclo-oxygenase 1 and 2 (COX1 and COX2), are involved in the production of PGE2. Unlike COX1, COX2 is an inducible enzyme that might be involved in the pathogenesis of lumbar disc herniation by upregulating PGE2 
production. High levels of PGE2 and COX2 have been observed in human herniated disc tissues [10, 18-20], and the resultant inflammatory reactions may cause low back pain or sciatica. Recent studies have revealed that PGE2 production increases in nucleus pulposus (NP) tissues under conditions of low tonicity [21], which may indicate that PGE2 plays an important role in the inflammatory reactions associated with IVD.

Il-17A is a cytokine that is mainly produced by activated Th17 cells and is required for the onset of several diseases, including rheumatoid arthritis [22, 23], asthma[24], inflammatory bowel disease[25] and lumbar disc herniation $[5,26,27]$. Previous studies have revealed that IL-7 can upregulate CCL20 production in NP cells to recruit Th17 cells to herniated disc tissues via the CCL20/CCR6 pathway, which increases IL-17 levels in disc tissue [5]. However, the manner and precise pathway by which IL-17 contributes to immune-mediated disc inflammation remain unclear. Cell metabolism in IVD tissues is mediated by various pathways. Mitogen-activated protein kinases (MAPKs) in chondrocytes and NP cells have received much attention. There are three major MAPKs, p38 kinase, c-Jun N-terminal kinase (JNK) and extracellular signal-regulated kinase (ERK), which participate in different signalling pathways to control cell growth, differentiation and apoptosis [28, 29]. Activator protein-1 (AP-1) is a downstream transcription factor in the MAPK pathway and can interact with specific DNA sequences called AP-1 sites [30]. It has been shown that the MAPK pathway plays a vital role in IVD degeneration [31-34]. Meanwhile, IL-17 was reported to display proinflammatory effects by activating the MAPK pathway in nerve cells and tumour cells [35-38].

How IL-17 contributes to the IVD inflammatory reaction is an important question. Identification of the downstream targets of IL-7 in IVD could advance our understanding of the mechanisms underlying IL-17-mediated IVD inflammation. NP cells are known targets of IL-17. In this study, we demonstrate that IL-17 enhances the expression of COX2 and PGE2 via activation of the MAPK/AP-1 pathway in NP cells, which leads to IVD inflammation and the development of LBP or sciatica. These findings may provide a new therapeutic approach for treating IVD inflammation and relieving LBP and sciatica.

\section{Methods}

\section{Ethics statement}

Specimens were collected from patients who underwent lumbar operations between February 2014 and April 2015 in Qilu Hospital of Shandong University, Jinan, China. The present study was approved by the Medical Ethical Committee of Shandong University Qilu Hospital.
Written informed consent documents were obtained from all patients involved in this research.

\section{Isolation and culture of primary IVD cells}

Human lumbar IVD samples that would have otherwise been discarded were obtained from patients undergoing posterior lumbar interbody fusion (PLIF) operations or lumbar discectomy surgeries for degenerative diseases $(\mathrm{n}=20$ patients, aged 21-45). Primary IVD cells were isolated and cultured as previously reported [5]. All of the samples were anonymized, and only patients' genders and ages were recorded. Disc tissues were transferred to the laboratory immediately. The discs were washed with cold, aseptic phosphate-buffered saline (PBS) to remove residual blood. IVD tissues were carefully separated and cut into fragments of approximately $1 \mathrm{~mm}^{3}$. The tissue samples were separately digested with trypsin and type II collagenase (Sigma-Aldrich, Ltd, China).NP cells were filtered through a 200-mesh sieve. The isolated NP cells were seeded as a monolayer and cultured in DMEM/ F12 media (Hyclone, Thermo Co., USA) containing $15 \%$ FCS and $1 \%$ PS under standard incubation conditions $\left(37^{\circ} \mathrm{C}, 95 \%\right.$ air, $\left.5 \% \mathrm{CO} 2, \mathrm{pH} 7.2\right)$ for approximately 3 weeks. After the primary cells adhered to the bottom of the culture bottle, the culture media was replaced every 3 days [39, 40]. When the NP cells were almost $80 \%$ confluent, the cells were dissociated with $5 \%$ trypsin and subcultured at a ratio of 1:3. Primary NP cells from passages 2 or 3 were harvested and cultured in 6-well plates in which IL-17A stimulation experiments could be performed. When the cells in the 6-well plates were approximately $70-80 \%$ confluent, they were cultured in serum-free medium for $12 \mathrm{~h}$ and treated with sterile PBS with or without recombinant IL-17A (PeproTech, USA). After differential cytokine treatment, the supernatants and NP cells were harvested for further analysis.

\section{Enzyme-linked immunosorbent assay (ELISA)}

Supernatants were collected from IL-17-treated and untreated NP cells. We measured PGE2 levels in supernatants from the conditioned NP cell cultures using a human PGE2 ELISA kit (BlueGene, China) according to the manufacturer's protocol. Colorimetric reactions were read at $540 \mathrm{~nm}$ on an Infinite M200 multifunction plate reader (Tecan scientific, Switzerland). PGE2 levels were normalized to total protein levels.

\section{Total protein and nuclear protein extraction and western blotting}

After the indicated treatment, the cultured NP cells were washed with PBS three times and placed in RIPA lysis buffer (Beyotime Biotechnology Co., Beijing, China) supplemented with $5 \%$ PMSF (a protease inhibitor). 
The cells were scraped from the plates, and the total protein lysates were transferred to microtubes and centrifuged at $15,000 \mathrm{rpm}$ for $15 \mathrm{~min}$ at $4{ }^{\circ} \mathrm{C}$. Nuclear proteins were extracted using a nuclear protein extraction kit (Beyotime Biotechnology Co., Ltd., Beijing, China) according to the manufacturer's instructions. The concentration of each protein sample was determined using a BCA protein assay kit (Beyotime Biotechnology Co., Beijing, China) according to the manufacturer's instructions. Equal amounts of protein $(10 \mu \mathrm{g})$ were subjected to $10 \%$ sodium dodecyl sulphate-polyacrylamide gel electrophoresis (SDS-PAGE) and subsequently transferred to polyvinylidene difluoride (PVDF) membranes. The PVDF membranes were blocked in $5 \%$ nonfat milk dissolved in $125 \mathrm{mM} \mathrm{NaCl}, 25 \mathrm{mM}$ Tris- $\mathrm{HCl}$ and $0.1 \%$ Tween 20 (TBST) for $3 \mathrm{~h}$ and then probed with relevant primary antibodies overnight at $4{ }^{\circ} \mathrm{C}$, followed by incubation with an immunoglobulin G-horseradish peroxidase (IgG-HRP) secondary antibody (1:2000; Golden Bridge Biotechnology Co., Ltd., Beijing, China) for $1 \mathrm{~h}$. The membranes were also probed with a rabbit anti-GAPDH antibody (1:4000, Abcam Biotechnology Co., USA) or a rabbit anti-lamin B antibody (1:4000, Abcam Biotechnology Co., USA) as a loading control. The following primary antibodies were used in this study: rabbit antip-p38, rabbitanti-p-JNK, rabbit anti-c-Jun (all 1:2000; Millipore Biotechnology Co., Ltd., America), mouse anti-p-ERK, mouse anti-c-Fos (all 1:2000; Millipore Biotechnology Co., Ltd., America), rabbit anti-COX2, rabbit anti-p38, rabbit anti-JNK, and rabbit anti-ERK1/2 (all 1:2000; Abcam Biotechnology Co., Ltd., United Kingdom). Protein bands were visualized using a FluorChemE chemiluminescent imaging system (Cell Biosciences, Santa Clara, CA) and quantified by densitometry analysis using Image J software (National Institutes of Health, USA). The integrated density data of target signals were normalized against reference data. The target/reference ratio represents the relative levels of each target protein.

\section{Immunofluorescence staining}

NP cells were transferred to a 24-well plate at a density of approximately $3 \times 10^{4}$ cells/well. The NP cells were cultured in serum-free medium for $12 \mathrm{~h}$ and then treated with either PBS or $100 \mathrm{ng} / \mathrm{ml} \mathrm{IL-17A}$ for $24 \mathrm{~h}$. The cells were then washed with cold PBS three times, fixed with $4 \%$ paraformaldehyde for $15 \mathrm{~min}$, permeabilized with $0.5 \%$ Triton X-100 for 10 min, blocked with $10 \%$ goat serum for $1 \mathrm{~h}$, and incubated with a primary antibody against p-c-Jun (1:400; Millipore Biotechnology Co., USA) overnight at $4{ }^{\circ} \mathrm{C}$. Then, the cells were washed three times and incubated with an anti-rabbit IgG secondary antibody (FITC) (1:100; Golden Bridge Biotechnology Co., Ltd., Beijing, China) for $1 \mathrm{~h}$ and
$10 \mu \mathrm{M}$ 4,6-diamidino-2-phenylindole (DAPI) for $15 \mathrm{~min}$ at room temperature to stain nuclei. The NP cells were also treated with either PBS or $100 \mathrm{ng} / \mathrm{ml} \mathrm{IL-17A} \mathrm{for}$ $15 \mathrm{~min}$, the cells were incubated with a primary antibody against p-p38 (1:400; Millipore Biotechnology Co., USA) overnight and an anti-rabbit IgG secondary antibody (TMRITC) (1:100; Golden Bridge Biotechnology Co., Ltd., Beijing, China) to perform an immunofluorescence test. The samples were observed using fluorescence microscopy.

\section{Statistical analysis}

All experiments were repeated at least three times, and all data points represent the mean \pm standard deviation of three independent experiments. Statistical analysis was performed using a two-tailed Student's $t$ test. A p value $<0.01$ (denoted with * or ${ }^{\#}$ ) was considered to be statistically significant.

\section{Results}

\section{Effects of IL-17A on COX2 and PGE2 production in primary} NP cells

Previous studies have shown that Th17 cells and IL-17A target NP cells in vitro and in vivo [5, 41]. In our study, when exposed to IL-17A treatment, primary NP cells responded by significantly increasing COX2 expression and PGE2 production relative to cytokine-free controls (Fig. 1). IL-17A alone enhanced COX2 expression in primary NP cells from degenerated IVD tissues in a concentration-dependent manner, with an optimal stimulation concentration of $100 \mathrm{ng} / \mathrm{ml}$ (Fig. 1a). Furthermore, the optimal concentration of IL-17A was used to treat NP cells for 6, 12 and $24 \mathrm{~h}$, and COX2 expression showed a statistically significant increase at $12 \mathrm{~h}$. An obvious timedependent effect on the expression of COX2 was also observed (Fig. 1b). Similar concentration-dependent and time-dependent trends were observed for PGE2 secretion from NP cells following stimulation with IL-17A (Fig. 1c, d). In conclusion, IL-17A significantly induced COX2 production and PGE2 secretion in NP cells.

\section{IL-17A induces activation of the JNK-MAPK and p38-MAPK pathways in primary NP cells}

To evaluate signalling pathway responses in NP cells activated by IL-17A, the MAPK pathway was examined. The expression levels of p-p38, P38, p-JNK, JNK, $\mathrm{p}$-ERK1/2 and ERK1/2 were analysed using western blots. The results demonstrated that IL-17A induced transient activation of the $\mathrm{p} 38$ MAPK pathway, resulting in elevated phosphorylation of p38 MAPK at15 min, which then phosphotylation level decreased, with levels remaining detectable through $120 \mathrm{~min}$ (Fig. 2a, d). What's more, the immunofluorescence test of p-p38 showed 

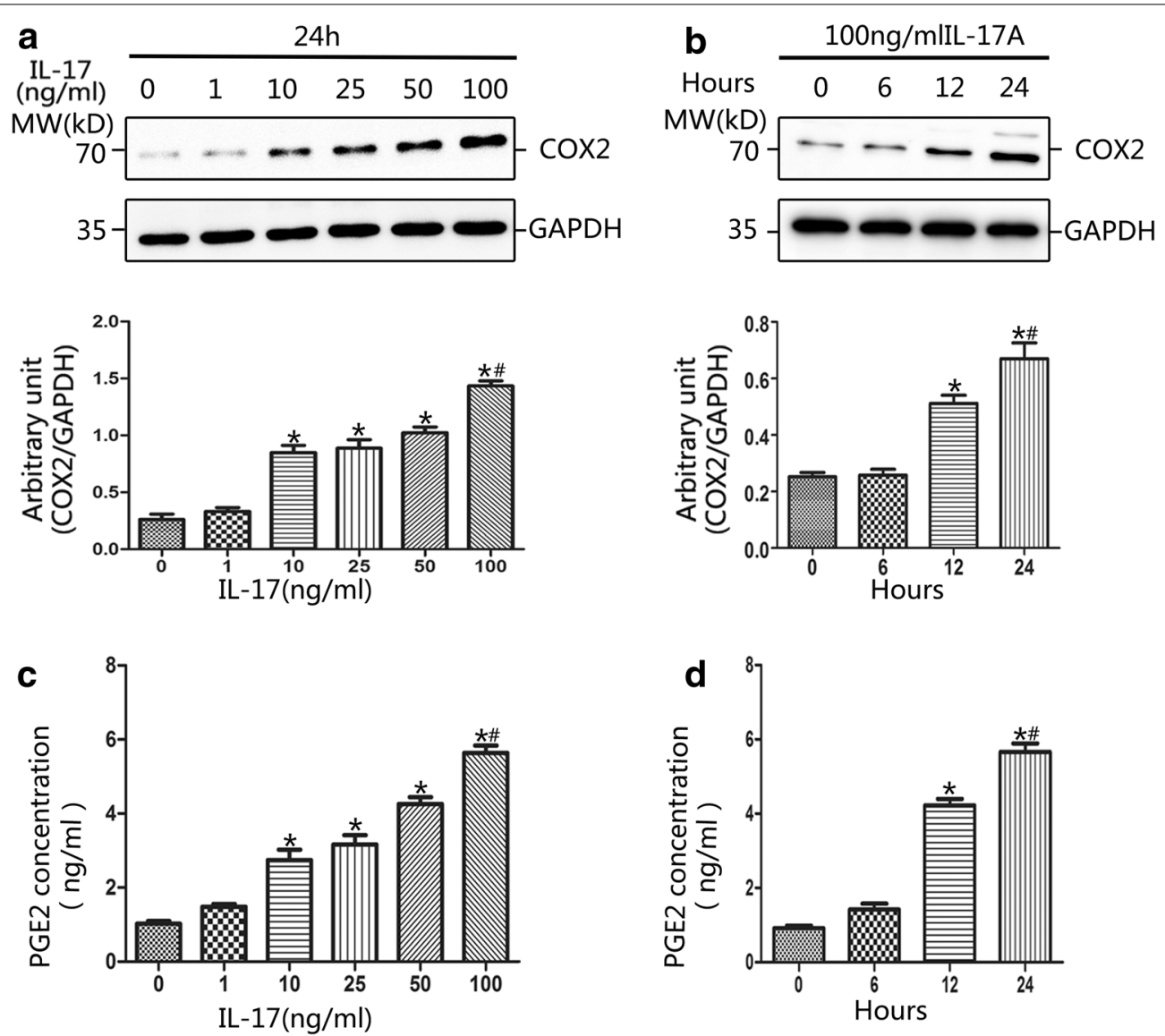

Fig. 1 Effect of IL-17A on expression of COX2 and PGE2 in NP cells. a IL-17A induced COX2 expression in a concentration-dependent manner. NP cells were stimulated with the indicated concentrations of IL-17A for $24 \mathrm{~h}$. Western blot analysis demonstrated that IL-17A of $10 \mathrm{ng} / \mathrm{ml}$ could significantly increase the COX2 expression and the optimal concentration was $100 \mathrm{ng} / \mathrm{ml}$. b IL-17A induced COX2 expression in a time-dependent manner. Cell cultures were treated with optimal concentration of IL-17A for 0, 6, 12 and $24 \mathrm{~h}$. Western blot results showed that IL-17A (100 ng/ml) could induce a time-dependent increase of COX2. c ELISA analysis revealed that IL-17A induced PGE2 secretion in a dose-dependent manner. The cell-free supernatants were harvested and the expression levels of PGE2 protein were quantified by ELISA. $\mathbf{d}$ IL-17A induced PGE2 secretion in a time-dependent manner. Regarding to both COX2 and PGE2, there were statistically significant differences between concentrations higher than $10 \mathrm{ng} / \mathrm{ml}$ and the control. And, statistical significance was verified of IL-17A treatment longer $12 \mathrm{~h}$. (a and $\mathbf{c}$ : ${ }^{*} \mathrm{P}<0.01$, vs. control; ${ }^{P} \mathrm{P}<0.001$, vs. $10 \mathrm{ng} / \mathrm{ml} ; \mathbf{b}$ and $\mathbf{d}:{ }^{*} \mathrm{P}<0.01$, vs. control; ${ }^{\#} \mathrm{P}<0.001$, vs. 12 h.)

that phosphorylation of p38 can be induced by IL-17A immediately (Fig. 3). Increased phosphorylation of JNK occurred within 15 min of IL-17A treatment and reached a peak level by $60 \mathrm{~min}$, remaining at a level higher than basal at 120 min (Fig. 2b, e). In contrast, the ERK/MAPK pathway was hardly activated following exposure to IL$17 \mathrm{~A}$, as the phosphorylation of ERK1/2 was not detectable even at 120 min (Fig. 2c, f).

\section{Regulation of COX2/PGE2 in response to IL-17A}

To investigate the involvement of the MAPK pathway in the regulation of COX2 and PGE2 levels following exposure to IL-17A, primary NP cell cultures were treated with pharmacological MAPK inhibitors. The P38 pathway was specifically blocked with SB203580, the JNK pathway with SP600125, and the ERK pathway with PD98059. Immunoblot analysis showed that inhibition of

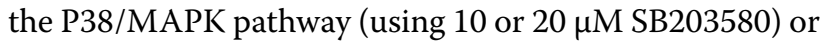
the JNK/MAPK pathway (using 10 or $20 \mu \mathrm{M}$ SP600125) significantly suppressed the IL-17A-stimulated upregulation of COX2 (Fig. 4a, b). Combination inhibition of both SB203580 and SP600125 were also performed, the results revealed that inhibition of both P38/MAPK pathway and JNK/MAPK pathways significantly decreased the expression of COX2 (Fig. 6b). In contrast, the upregulation of COX2 by IL-17A appeared to be independent of the ERK/MAPK pathway, as the elevated level of COX2 was unaffected by selective inhibition of the ERK pathway (using 20 or $30 \mu$ M PD98059) (Fig. 4c). Similar trends were observed in the PGE2 ELISA results when 


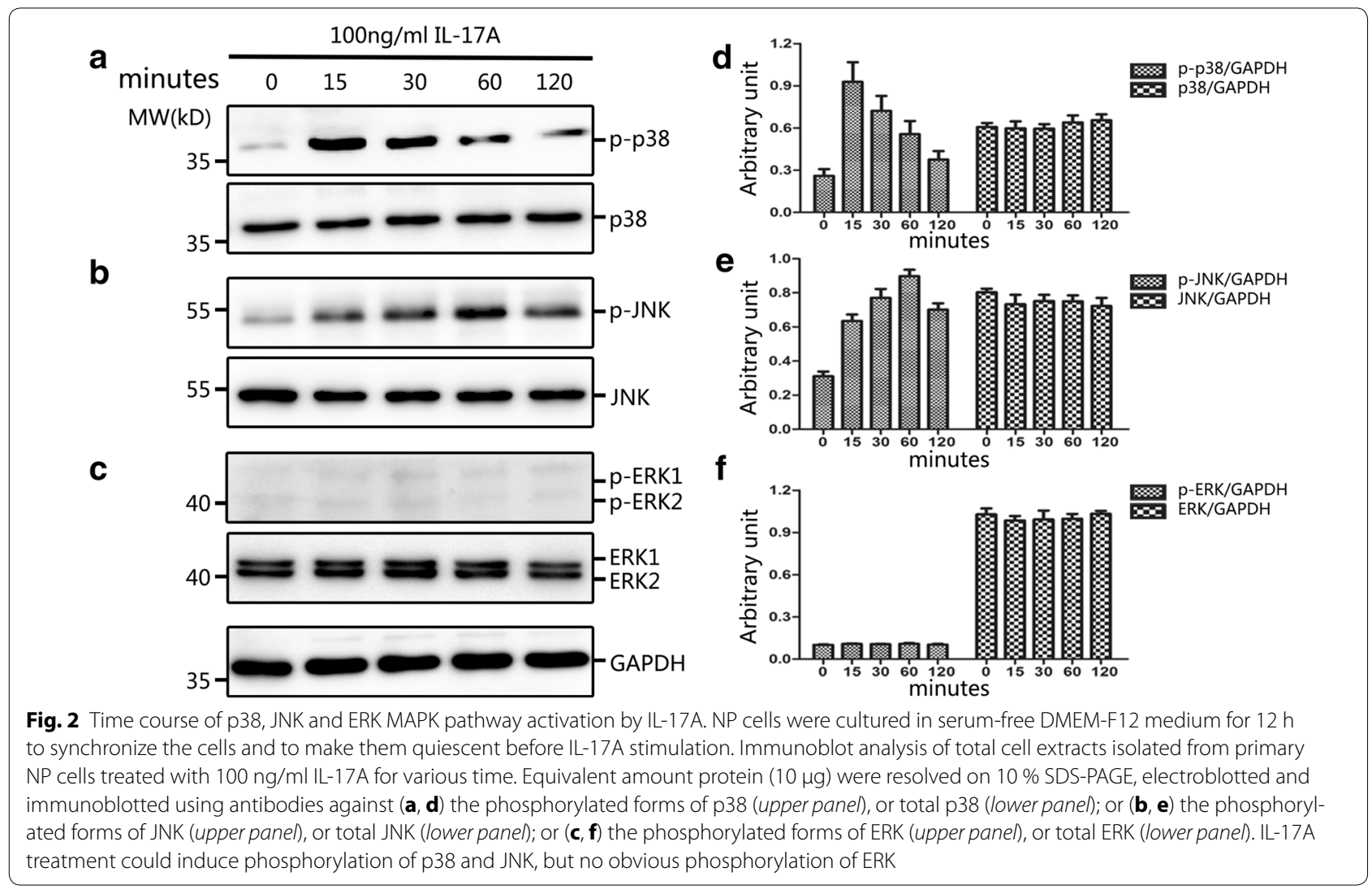

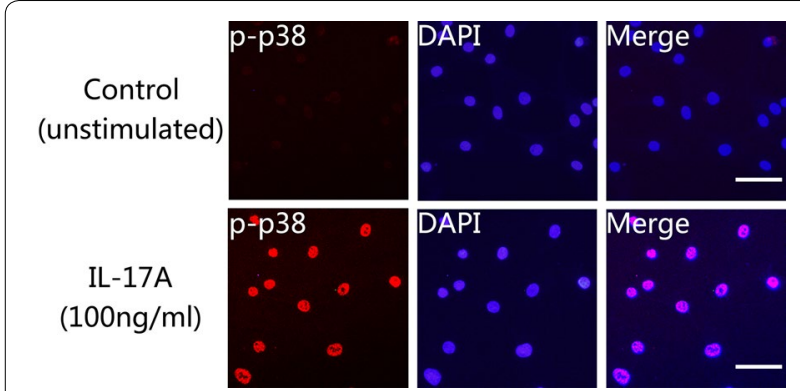

Fig. 3 IL-17A induces phosphorylation and activation of p38 in NP cells. NP cells were transferred to a 24-well plate and cultured in serum-free medium for $12 \mathrm{~h}$ before treatment with IL-17A (100 ng/ $\mathrm{ml}$ ) for $15 \mathrm{~min}$. The cells were then performed to Immunofluorescence staining. NP cells were incubated with primary antibodies against p-p38 and anti-rabbit lgG secondary antibody (TMRITC). DAPI mounting medium was used for nuclear staining. Left: cells stained with antibody to p-p38 (red). Middle: cells stained with DAPI to identify nuclei, (blue). Right: cells stained with antibody to p-c-Jun and with DAPI. The results revealed that phosphorylation level of p38 was promoted significantly in IL-17A treated NP cells than in untrated controls. Scale bar $=50 \mu \mathrm{m}$ using selective P38, JNK and ERK MAPK pathway inhibitors (Figs. $4 \mathrm{~d}-\mathrm{f}, 6 \mathrm{~b}$ ). These results suggest that the P38/ MAPK and JNK/MAPK pathways regulate COX2 and PGE2 expression in primary NP cells.

\section{IL-17A-mediated upregulation of COX2 and PGE2 in primary NP cells via the P38/C-Fos and JNK/C-Jun signalling pathways}

The results described above indicated that activation of the p38 and JNK MAPK pathways is involved in IL17A-mediated induction of COX2 and PGE2 expression. Additionally, the COX2 promoter has been shown to contain a motif recognized by the transcription factor AP-1 [42], which is composed of c-Jun and c-Fos [30]. To identify the signalling cascades by which IL-17A stimulated MAPK activation, we first used immunofluorescence staining to detect the phosphorylation of c-Jun. The results revealed that IL-17A appeared to stimulate the phosphorylation of c-Jun and that this process could be weakened by blocking the JNK pathway (Fig. 5). This 


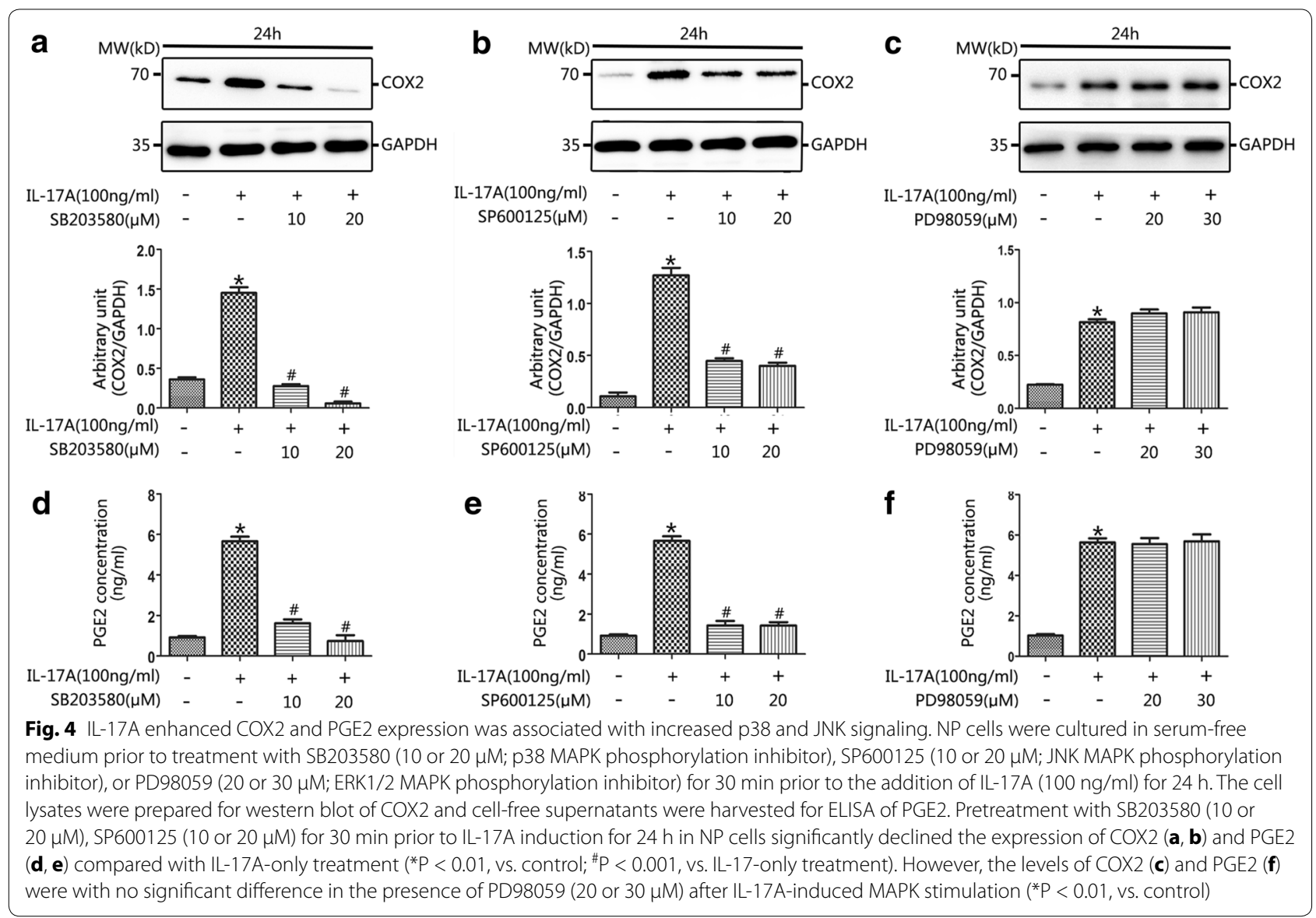

indicated that IL-17A activates phosphorylation of c-Jun via the JNK/MAPK pathway. Furthermore, we examined the effects of IL-17A on the translocation of AP-1, c-Jun and c-Fos. The results indicated that the translocation of both c-Jun and c-Fos, which are the major downstream components of MAPKs, was significantly upregulated by IL-17A (Fig. 6). To further explore the effect of IL-17A-mediated regulation of AP-1 transactivation, we extracted nuclear protein and examined the abilities of MAPK inhibitors to inhibit AP-1 transactivation using western blotting. We observed that the P38 inhibitor SB203580 (10 or $20 \mu \mathrm{M}$ ) could interfere with nuclear c-Fos translocation in NP cells, while the JNK inhibitor SP600125 (10 or $20 \mu \mathrm{M})$ downregulated c-Jun nuclear translocation (Fig. 6a). This suggests that c-Fos and c-Jun translocation was upregulated by P38 and JNK phosphorylation, respectively. To further clarify the involvement of AP-1 in IL-17A-induced COX2/ PGE2 expression, NP cells were cultured with IL-17A with or without curcumin $(30 \mu \mathrm{M})$. Curcumin $(30 \mu \mathrm{M})$ significantly downregulated COX2/PGE2 expression (Fig. 6c). Based on these data, we deduced that stimulation of COX2 and PGE2 expression by IL-17A requires activation of P38/c-Fos and JNK/c-Jun via the AP-1 signalling pathway.

\section{Discussion}

It has been shown that inflammation plays a vital role in the pathogenic processes underlying painful IVD degenerative diseases $[6,11,43,44]$. Furthermore, previous studies have reported that Th17 cells are recruited to herniated disc tissues and produce IL-17A, stimulating proinflammatory processes [5]. Other studies of IVD cells have demonstrated that IL-17, either alone or in combination with TNF- $\alpha$ and IFN $\gamma$, can trigger the production of inflammatory stimulators, including NOx, IL-6 and PGE2 [41]. The results of our study demonstrated that human NP cells respond to IL-17A by increasing COX2 and PGE2 production. One of the pro-inflammatory effects of IL-17A depends on its capacity to enhance the expression of COX2, which plays a pivotal role in upregulation of PGE2. In IVD herniation and other degenerative disc diseases, abundant production of PGE2 is considered to be the main cause of LBP and sciatica [18]. In the current study, a dramatic increase in COX2 expression and PGE2 release was observed in NP cells following 
treatment with IL-17A, which suggests that IL-17A has a key role in the inflammatory process underlying IVD disease.

To date, the intracellular mechanism of IL-17A-mediated regulation of COX2 expression and subsequent PGE2 release in NP cells has not been elucidated. Previous studies have implied that IL-17 plays an important role in multiple sclerosis via the MAPK pathway $[36,45]$. Additional roles have been suggested for IL-17 in human pulpitis [46] and glioma [38]. In the present study, we determined that the MAPK pathway is involved in regulating IL-17A-induced production of COX2 and PGE2 in NP cells. Primary NP cell cultures were treated with $100 \mathrm{ng} / \mathrm{ml} \mathrm{IL-17A}$ for $24 \mathrm{~h}$. Our results provided evidence that exposure to exogenous IL-17A markedly increased the phosphorylation of p38 and JNK but did not increase the phosphorylation of ERK (Figs. 2, 3). Interestingly, pretreatment with the p38 inhibitor SB203580 and the JNK inhibitor SP600125 effectively attenuated IL-17A-induced COX2 and PGE2 expression (Figs. 4, 6b). This inhibition was not found following pretreatment with the ERK inhibitor PD98059. The role of the MAPK pathway in regulating COX2 and PGE2 production was demonstrated, as attenuation of both p38 and JNK signalling pathways significantly abrogated IL-17A-mediated COX2 and PGE2 expression.

In addition to the NP cells in our study, COX2 expression has been observed to be induced by AP-1, which regulates the expression of several genes, in epithelial cells [42] and fibroblasts [47]. Furthermore, overexpression of c-Fos in NP cells increased the IVD degenerative process [32]. In the present study, we attempted to clarify the possible molecular mechanisms by which IL-17A upregulates the expression of COX2 and PGE2. Interestingly, we observed that IL-17A remarkably promoted the phosphorylation of c-Jun (Fig. 5). As previously reported, c-Jun is not only a downstream transcription factor in the MAPK pathway but also a target of JNK [30]. JNK activation induces the phosphorylation of c-Jun, which then promotes the expression of c-Jun. Moreover, the present study showed that IL-17A induced the nuclear translocation of c-Jun and c-Fos, which could be effectively inhibited by the JNK inhibitor SP600125 or the p38 inhibitor SB203580 (Fig. 6a). Further studies revealed that inhibition of AP-1 activation by curcumin significantly reduced COX2 expression and PGE2 production (Fig. 6c). What' more, an interesting result was that when either p38/cFos or JNK/c-Jun pathway is inhibited, the productions of COX2 or PGE2 were decreased by more than $70 \%$. We assume the reason was that AP-1 was existed and functioned in the form of heterodimers of $c$-jun and c-fos, in the expression of COX2, both c-jun and c-fos were

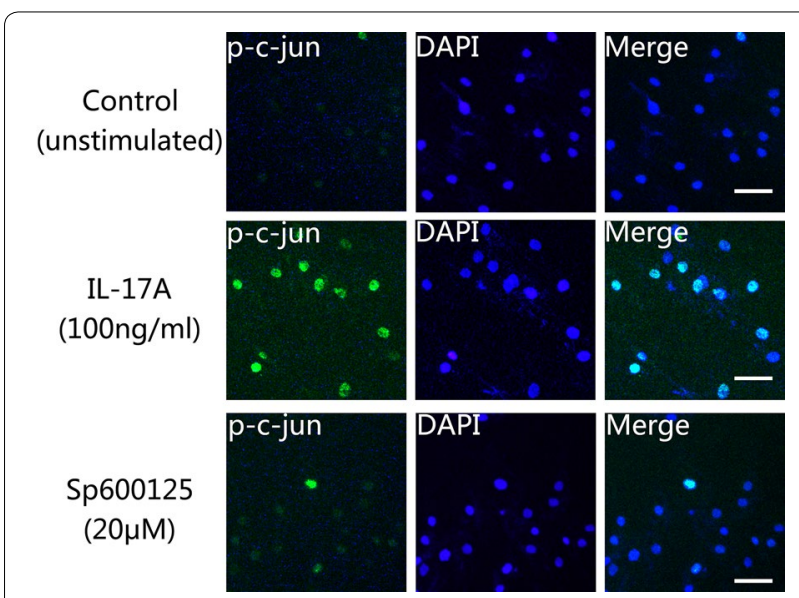

Fig. 5 IL-17A induces phosphorylation of c-Jun in NP cells. Primary NP cells were transferred to a 24-well plate and cultured in serum-free medium for $12 \mathrm{~h}$ before treatment with SP600125 (20 $\mu \mathrm{M}$; JNK MAPK phosphorylation inhibitor) for 30 min prior to the addition of IL-17A (100 ng/ml) for $4 \mathrm{~h}$. The cells were performed to Immunofluorescence staining. NP cells were incubated with primary antibodies against p-c-jun and anti-rabbit IgG secondary antibody (FITC). DAPI mounting medium was used for nuclear staining. Left: cells stained with antibody to p-c-Jun. Middle: cells stained with DAPI to identify nuclei, (blue). Right: cells stained with antibody to $\mathrm{p}$-c-Jun and with DAPI. The phosphorylation level of c-Jun was promoted strongly in IL-17A treated NP cells than in untrated controls, and the phosphorylation induced by IL-17A can be attenuated by JNK inhibitor SP600125 $(20 \mu \mathrm{M})$. Scale bar $=50 \mu \mathrm{m}$

needed to form AP-1 heterodimers and activated, then bind to the AP- 1 binding site to promote COX2 expression. In summary, we suggest that IL-17A-induced COX2 expression and PGE2 production are AP-1-dependent processes that act through parallel signalling cascades involving $\mathrm{p} 38 / \mathrm{c}$-Fos and JNK/c-Jun.

Previous studies have shown that Th17 cells contribute to IVD inflammation both directly and indirectly $[5,27$, 41]. Based on previous evidence of the pro-inflammatory activities of IL-17A, for the first time, we described a hypothetical model elucidating the potential mechanisms by which IL-17A induces COX2 expression and PGE2 production in NP cells (Fig. 7). In our model, peripheral Th17 cells are transferred to the IVD to secrete IL-17A. In the inflammatory microenvironment, IL-17A activates IL-17 receptors on NP cell membranes and triggers p38 and JNK activation, thereby inducing the phosphorylation of c-Jun and the translocation of c-Fos and c-Jun. $\mathrm{C}$-Fos and c-Jun then cooperatively bind to the AP1-binding site and promote COX2 expression and subsequent PGE2 production. SB203580 acts as an inhibitor of the p38 signalling pathway, while SP600125 inhibits the JNK pathway, suppressing IL-17A-induced MAPK activation and COX2 expression. 

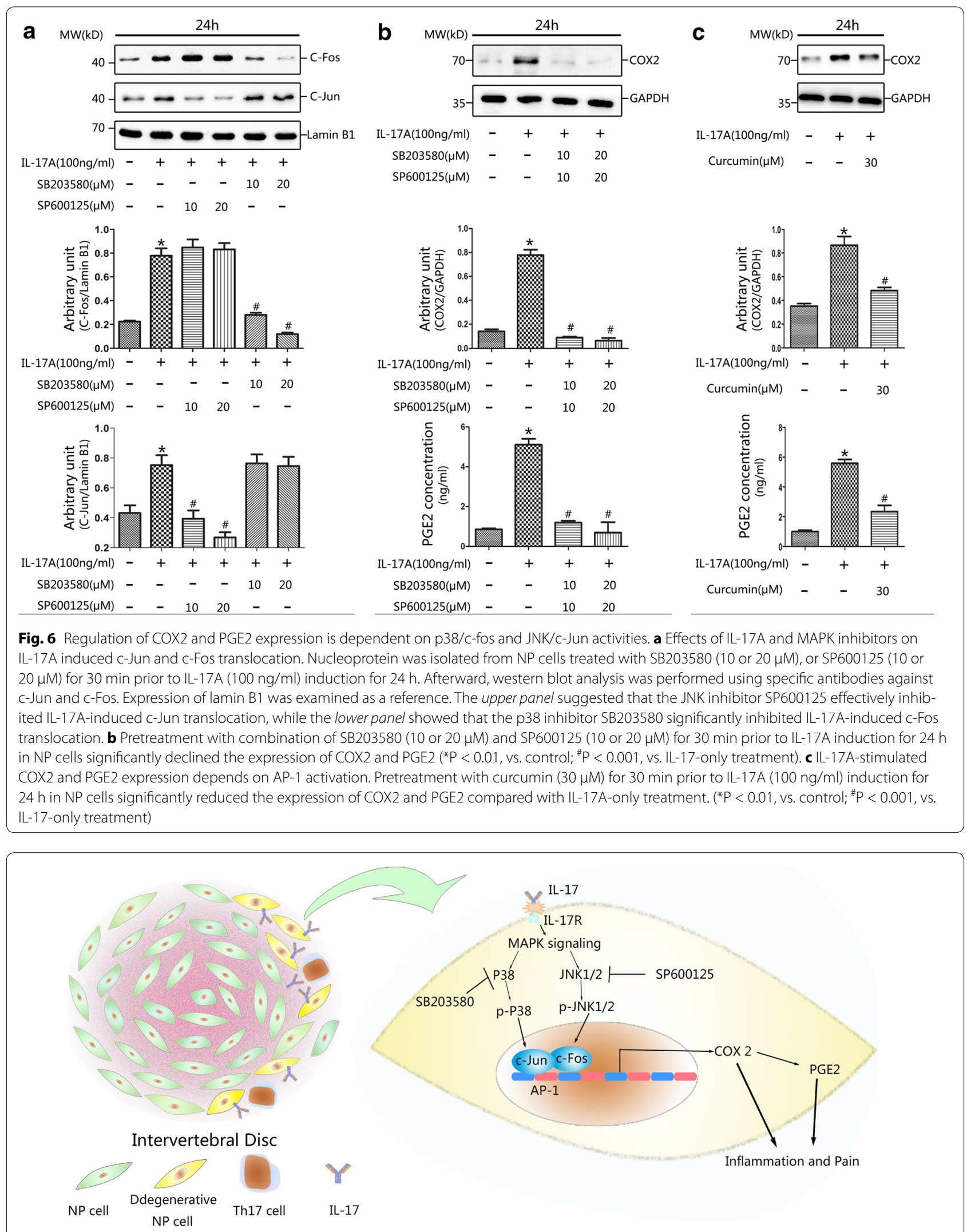

Fig. 7 Schematic model of the proposed signal pathways of inflammation induced by IL-17A 
In our study, p38-MAPK and JNK-MAPK inhibition significantly reduced the induction of COX2 expression by IL-17A. This suggests that inhibition of MAPK/AP-1 activation by different pharmacological agents might be useful against IL-17-induced COX2/PGE2 production and IVD inflammation. This may provide a potential therapeutic target to ameliorate IVD inflammation. However, another important factor to be considered is that inhibition of the MAPK pathway might result in severe cytotoxicity in NP cells [6]. Strict screening is necessary before MAPK inhibitors can be used to treat IVD inflammation.

\section{Conclusion}

In conclusion, our results revealed that IL-17A exerts pro-inflammatory effects by increasing COX2/PGE2 production in NP cells through activation of the MAPK pathway in an AP-1-dependent manner.

\section{Abbreviations}

LBP: Iow back pain; IVD: intervertebral disc; NP: nucleus pulposus; PLIF: posterior lumbar interbody fusion; PBS: phosphate-buffered saline.

\section{Authors' contributions}

$J K L, L N, L C$ and YPZ participated in study design, data analysis and draft the manuscript. YQZ, XQW participated in data analysis. JKL, SSW, YL, HZ and LC carried out the immunoassays and ELISA. All authors read and approved the final manuscript.

\section{Author details \\ ${ }^{1}$ Department of Orthopaedic Surgery, Qilu Hospital, Shandong University, Jinan 250012, Shandong, People's Republic of China. ${ }^{2}$ Department of Ortho- paedic Surgery, Shanghai Ninth People's Hospital, Shanghai 200011, People's Republic of China. ${ }^{3}$ Qilu Hospital Shandong University, No.107, Wen Hua Xi Road, Jinan 250012, Shandong, People's Republic of China.}

\section{Acknowledgements \\ This study was financially supported by funding from the National Natural Science Foundation of China (Nos. 81572191, 81501880, 30700852 and 81272036), and the Natural Science Foundation of Shandong Province (ZR2013HM095). The funders played no role in study design, data collection, data analysis, decision to publish, or preparation of the manuscript.}

\section{Competing interests}

The authors declare that they have no competing interests.

Received: 2 October 2015 Accepted: 7 March 2016

Published online: 17 March 2016

\section{References}

1. Hoy D, Bain C, Williams G, March L, Brooks P, Blyth F, Woolf A, Vos T, Buchbinder R. A systematic review of the global prevalence of low back pain. Arthritis Rheum. 2012;64:2028-37.

2. Linder M, Michaelson P, Roijezon U. Laterality judgments in people with low back pain: a cross-sectional observational and test-retest reliability study. Man Ther. 2015

3. Simon J, McAuliffe M, Shamim F, Vuong N, Tahaei A. Discogenic low back pain. Phys Med Rehabil Clin N Am. 2014;25:305-17.

4. Naylor A, Happey F, Turner RL, Shentall RD, West DC, Richardson C. Enzymic and immunological activity in the intervertebral disk. Orthop Clin North Am. 1975;6:51-8.
5. Zhang W, Nie L, Wang Y, Wang XP, Zhao H, Dongol S, Maharjan S, Cheng L. CCL20 Secretion from the Nucleus Pulposus Improves the Recruitment of CCR6-Expressing Th17 Cells to Degenerated IVD Tissues. PLoS One. 2013:8:e66286.

6. Molinos M, Almeida CR, Caldeira J, Cunha C, Goncalves RM, Barbosa MA. Inflammation in intervertebral disc degeneration and regeneration. J R Soc Interface. 2015:12:20141191.

7. Di Martino A, Merlini L, Faldini C. Autoimmunity in intervertebral disc herniation: from bench to bedside. Expert Opinion on Therapeutic Targets. 2013;17:1461-70.

8. Podichetty VK. The aging spine: the role of inflammatory mediators in intervertebral disc degeneration. Cell Mol Biol (Noisy-le-grand). 2007:53:4-18.

9. Iwabuchi S, Ito M, Chikanishi T, Azuma Y, Haro H. Role of the tumor necrosis factor-alpha, cyclooxygenase-2, prostaglandin E2, and effect of low-intensity pulsed ultrasound in an in vitro herniated disc resorption model. J Orthop Res. 2008;26:1274-8.

10. Takada T, Nishida K, Maeno K, Kakutani K, Yurube T, Doita M, Kurosaka M. Intervertebral disc and macrophage interaction induces mechanical hyperalgesia and cytokine production in a herniated disc model in rats. Arthritis Rheum. 2012;64:2601-10.

11. Burke JG, Watson RW, McCormack D, Dowling FE, Walsh MG, Fitzpatrick $J M$. Intervertebral discs which cause low back pain secrete high levels of proinflammatory mediators. J Bone Joint Surg Br. 2002;84:196-201.

12. Yoshida M, Nakamura T, Sei A, Kikuchi T, Takagi K, Matsukawa A. Intervertebral disc cells produce tumor necrosis factor alpha, interleukin-1 beta, and monocyte chemoattractant protein-1 immediately after herniation: an experimental study using a new hernia model. Spine (Phila Pa 1976). 2005:30:55-61.

13. Ahn SH, Cho YW, Ahn MW, Jang SH, Sohn YK, Kim HS. mRNA expression of cytokines and chemokines in herniated lumbar intervertebral discs. Spine (Phila Pa 1976). 2002;27:911-7.

14. Li H, Zou X, Baatrup A, Lind M, Bunger C. Cytokine profiles in conditioned media from cultured human intervertebral disc tissue. Implications of their effect on bone marrow stem cell metabolism. Acta Orthop. 2005;76:115-21.

15. Kang JD, Georgescu HI, Mclntyre-Larkin L, Stefanovic-Racic M, Donaldson WF 3rd, Evans CH. Herniated lumbar intervertebral discs spontaneously produce matrix metalloproteinases, nitric oxide, interleukin-6, and prostaglandin E2. Spine (Phila Pa 1976). 1996;21:271-7.

16. Andrade P, Visser-Vandewalle V, Philippens M, Daemen MA, Steinbusch HW, Buurman WA, Hoogland G. Tumor necrosis factor-alpha levels correlate with postoperative pain severity in lumbar disc hernia patients: opposite clinical effects between tumor necrosis factor receptor 1 and 2 . Pain. 2011;152:2645-52.

17. Takahashi H, Suguro T, Okazima Y, Motegi M, Okada Y, Kakiuchi T. Inflammatory cytokines in the herniated disc of the lumbar spine. Spine (Phila Pa 1976). 1996;21:218-24.

18. Miyamoto H, Saura R, Harada T, Doita M, Mizuno K. The role of cyclooxygenase-2 and inflammatory cytokines in pain induction of herniated lumbar intervertebral disc. Kobe J Med Sci. 2000;46:13-28.

19. Miyamoto H, Saura R, Doita M, Kurosaka M, Mizuno K. The role of cyclooxygenase-2 in lumbar disc herniation. Spine (Phila Pa 1976). 2002;27:2477-83.

20. O'Donnell JL, O'Donnell AL. Prostaglandin E2 content in herniated lumbar disc disease. Spine (Phila Pa 1976). 1996;21:1653-5 (discussion 1655-1656).

21. van Dijk B, Potier E, van Dijk M, Langelaan M, Papen-Botterhuis N, Ito K. Reduced tonicity stimulates an inflammatory response in nucleus pulposus tissue that can be limited by a COX-2-specific inhibitor. J Orthop Res. 2015;33:1724-31.

22. Crome SQ, Wang AY, Levings MK. Translational mini-review series on Th17 cells: function and regulation of human Thelper 17 cells in health and disease. Clin Exp Immunol. 2010;159:109-19.

23. Hirota K, Yoshitomi H, Hashimoto M, Maeda S, Teradaira S, Sugimoto N, Yamaguchi T, Nomura T, Ito H, Nakamura T, et al. Preferential recruitment of CCR6-expressing Th17 cells to inflamed joints via CCL20 in rheumatoid arthritis and its animal model. J Exp Med. 2007;204:2803-12.

24. Bullens DM, Truyen E, Coteur L, Dilissen E, Hellings PW, Dupont LJ, Ceuppens JL. IL-17 mRNA in sputum of asthmatic patients: linking $T$ cell driven inflammation and granulocytic influx? Respir Res. 2006;7:135. 
25. Abraham C, Cho J. Interleukin-23/Th17 pathways and inflammatory bowel disease. Inflamm Bowel Dis. 2009;15:1090-100.

26. Zhang W, Nie L, Guo YJ, Han LX, Wang X, Zhao H, Han YG, Zhang YQ, Cheng $\mathrm{L}$. Th17 cell frequency and IL-17 concentration correlate with pre- and postoperative pain sensation in patients with intervertebral disk degeneration. Orthopedics. 2014;37:e685-91.

27. Cheng L, Fan W, Liu B, Wang X, Nie L. Th17 lymphocyte levels are higher in patients with ruptured than non-ruptured lumbar discs, and are correlated with pain intensity. Injury. 2013;44:1805-10.

28. Marshall CJ. Specificity of receptor tyrosine kinase signaling: transient versus sustained extracellular signal-regulated kinase activation. Cell. 1995;80:179-85.

29. Ip YT, Davis RJ. Signal transduction by the c-Jun N-terminal kinase (JNK)from inflammation to development. Curr Opin Cell Biol. 1998;10:205-19.

30. Angel P, Imagawa M, Chiu R, Stein B, Imbra RJ, Rahmsdorf HJ, Jonat C, Herrlich P, Karin M. Phorbol ester-inducible genes contain a common cis element recognized by a TPA-modulated trans-acting factor. Cell. 1987;49:729-39.

31. Kim JH, Studer RK, Vo NV, Sowa GA, Kang JD. p38 MAPK inhibition selectively mitigates inflammatory mediators and VEGF production in AF cells co-cultured with activated macrophage-like THP-1 cells. Osteoarthritis Cartilage. 2009;17:1662-9.

32. Yokoyama K, Hiyama A, Arai F, Nukaga T, Sakai D, Mochida J. C-Fos regulation by the MAPK and PKC pathways in intervertebral disc cells. PLoS One. 2013;8:e73210

33. Studer RK, Aboka AM, Gilbertson LG, Georgescu H, Sowa G, Vo N, Kang JD. p38 MAPK inhibition in nucleus pulposus cells: a potential target for treating intervertebral disc degeneration. Spine (Phila Pa 1976). 2007;32:2827-33.

34. Studer RK, Gilbertson LG, Georgescu H, Sowa G, Vo N, Kang JD. p38 MAPK inhibition modulates rabbit nucleus pulposus cell response to IL-1. J Orthop Res. 2008;26:991-8.

35. Zhao J, Liu J, Denney J, Li C, Li F, Chang F, Chen M, Yin D. TLR2 involved in naive $C D 4+T$ cells rescues stress-induced immune suppression by regulating Th1/Th2 and Th17. Neuroimmunomodulation. 2015.

36. Huang G, Wang Y, Vogel P, Chi H. Control of IL-17 receptor signaling and tissue inflammation by the p38alpha-MKP-1 signaling axis in a mouse model of multiple sclerosis. Sci Signal. 2015;8:ra24.
37. Wang K, Kim MK, Di Caro G, Wong J, Shalapour S, Wan J, Zhang W, Zhong Z, Sanchez-Lopez E, Wu LW, et al. Interleukin-17 receptor a signaling in transformed enterocytes promotes early colorectal tumorigenesis. Immunity. 2014;41:1052-63.

38. Ma X, Reynolds SL, Baker BJ, Li X, Benveniste EN, Qin H. IL-17 enhancement of the IL-6 signaling cascade in astrocytes. J Immunol. 2010;184:4898-906

39. Hiyama A, Sakai D, Risbud MV, Tanaka M, Arai F, Abe K, Mochida J. Enhancement of intervertebral disc cell senescence by WNT/betacatenin signaling-induced matrix metalloproteinase expression. Arthritis Rheum. 2010;62:3036-47.

40. Hutton WC, Elmer WA, Bryce LM, Kozlowska EE, Boden SD, Kozlowski M. Do the intervertebral disc cells respond to different levels of hydrostatic pressure? Clin Biomech (Bristol, Avon). 2001;16:728-34.

41. Gabr MA, Jing L, Helbling AR, Sinclair SM, Allen KD, Shamji MF, Richardson WJ, Fitch RD, Setton LA, Chen J. Interleukin-17 synergizes with IFNgamma or TNFalpha to promote inflammatory mediator release and intercellular adhesion molecule-1 (ICAM-1) expression in human intervertebral disc cells. J Orthop Res. 2011;29:1-7.

42. Park SA, Kim EH, Na HK, Surh YJ. KG-135 inhibits COX-2 expression by blocking the activation of JNK and AP-1 in phorbol ester-stimulated human breast epithelial cells. Ann N Y Acad Sci. 2007;1095:545-53.

43. Peng Y, Lv FJ. Symptomatic versus asymptomatic intervertebral disc degeneration: is inflammation the key? Crit Rev Eukaryot Gene Expr. 2015;25:13-21.

44. Sakai D, Grad S. Advancing the cellular and molecular therapy for intervertebral disc disease. Adv Drug Deliv Rev. 2015;84:159-71.

45. Gaffen SL, McGeachy MJ. Integrating p38alpha MAPK immune signals in nonimmune cells. Sci Signal. 2015;8:fs5.

46. Xiong H, Wei L, Peng B. IL-17 stimulates the production of the inflammatory chemokines IL-6 and IL-8 in human dental pulp fibroblasts. Int Endod J. 2015;48:505-11.

47. Tsai MH, Lin ZC, Liang CJ, Yen FL, Chiang YC, Lee CW. Eupafolin inhibits PGE2 production and COX2 expression in LPS-stimulated human dermal fibroblasts by blocking JNK/AP-1 and Nox2/p47(phox) pathway. Toxicol Appl Pharmacol. 2014;279:240-51.

\section{Submit your next manuscript to BioMed Central and we will help you at every step:}

- We accept pre-submission inquiries

- Our selector tool helps you to find the most relevant journal

- We provide round the clock customer support

- Convenient online submission

- Thorough peer review

- Inclusion in PubMed and all major indexing services

- Maximum visibility for your research

Submit your manuscript at www.biomedcentral.com/submit

\section{() Biomed Central}

